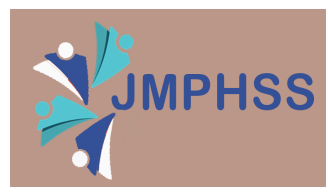

Journal of Management Practices, Humanities and Social Sciences

Vol 3 Issue 1 pp. 6-11

https://doi.org/10.33152/jmphss-3.1.2

\title{
ORIGINAL CONTRIBUTION \\ Changing Relations Between Fan Cultures and Industry: The Legitimation Paradox
}

\author{
Judith Fathallah* \\ Solent University, Southampton, England
}

\begin{abstract}
The study aims to observe the deconstruction of the legitimation paradox at work, as the legitimacy of authorship itself begins to be questioned. It was most clear in metatextual styles of fanfic which reflected on its own relationship with the source text, and the showrunners' attempts at containment, which were then complicated by fandom's re-(re!)appropriation of control of the narrative, often with explicit reflection on the process. This article first explains the methodology that was developed, and makes the broader case for utilizing discourse analysis as a tool in studying fanwork. Using the cult television texts Sherlock (BBC), Game of Thrones (HBO) and Supernatural (CW) as a case study, discourse theory adapted from Foucault was utilized to establish that discursive formations from the source text can be de- and re-constructed, sometimes consolidating canon's constructions, but at other times, altering other characterizations and criticizing statements from canon. Multi-modal tools of fanvids, artwork, and even musical conventions have been utilized in the current study. The findings explained how changing media affordances of sites like Tumblr critique and undermine traditional conceptions of authorship and authority through their structure as modes of engagement as much as their content, and finally suggest some strategies of engagement for industry professionals.
\end{abstract}

Index Terms - Faniction, Fan Culture and Industry, Discourse Analysis, Legitimation Paradox.

Received: 02 February 2019; Accepted: 15 March 2019; Published: 27 June 2019

\section{Introduction}

The ways that fans engage with their preferred media are changing and expanding rapidly. Over the past ten years, we have seen rapid growth online of creative communities devoted to producing and sharing fanart, costuming, translating, subtitling, game modification and more. Fanfiction, the unauthorized rewriting and adaptation of corporately owned media, is the fastest growing form of writing in the world (De Kosnik, 2016; Mirmohamadi, 2014). Though its ultimate origins are in pre-Gutenberg, communal forms of storytelling, its modern articulations really begin with the hardcopy fanzines television fans created in the 60 s for circulation within closed communities. Nowadays, fanfic operates almost entirely online, and had obtained unprecedented popularity and visibility. Despite increasing professionalization of this and author forms of fan creativity, fanfiction rarely commands the sort of credibility or cultural kudos associated with professional writing, and may even be constructed as vaguely risible in the popular press.

Beginning in 2013, the present researcher designed and conducted the first large scale discourse analysis to address fanfiction. Like most forms of discourse analysis, it was concerned not only with the construction and consolidation of social ideology but with processes of change: how discourse is solidified, adapted and/or undermined. In the work eventually published as Fanfiction and the Author: How Fanfic Changes
Popular Cultural Texts (Fathallah, 2017), it established that fanfic operates through a paradox of legitimation. Through this process, fanfic attempts to legitimate itself through appeal to the very construction of authorship it subverts, an ultimately Romantic conception of the lone male genius imbued with the powers of originality. Using the current cult texts Sherlock (BBC), Game of Thrones (HBO) and Supernatural (CW) as a case the study, discourse theory adapted from Foucault was utilized to establish that discursive formations from the source text can be de- and re-constructed, sometimes consolidating canon's constructions, but at other times, altering Othered characterizations and criticizing statements from canon. Paradoxically, however, this process utilizes and functions through the capital of the already-empowered: the White male author (Hills, 2003, 2010; Gray, 2010; Scott, 2011), and/or the white male protagonists of the series (Dyer, 1997). The formations selected for analysis built upon each other to demonstrate this construction: first, (White) masculinity in the BBC's Sherlock; second, authority in HBO's Game of Thrones; and finally authorship in the CW's Supernatural. In this last and most explicit clearest example, the fan's writing is legitimated by the TV-auteur who appears as a character in the series. The fan is simultaneously empowered and contained as showrunners grant metatextual acknowledgment of and paratextual permission for fanfic via its inclusion in the show. Derivative writing which changes popular culture is legitimated and empowered because and so far as the canonical author says so. By the conclusion,

\footnotetext{
*Email: judith.fathallah@solent.ac.uk
} 
however, the study had begun to observe the deconstruction of the legitimation paradox at work, as the legitimacy of authorship itself begins to be questioned. This was most clear in metatextual styles of fanfic which reflected on its own relationship with the source text, and the showrunners' attempts at containment, which were then complicated by fandom's re-(re!)appropriation of control of the narrative, often with explicit reflection on the process. This article first explains the methodology that was developed, and makes the broader case for utilizing discourse analysis as a tool in studying fanwork. The primary focus was formerly written text, but the researcher has since gone on to utilize multi-modal tools in the study of fanvids, artwork, gifs, and even musical conventions. The second part of this article will therefore, explain how changing media affordances of sites like Tumblr critique and undermine traditional conceptions of authorship and authority through their structure as modes of engagement as much as their content, and suggest some strategies of engagement for industry professionals. This research has established that the operations of the legitimation paradox have underpinned a great deal of fanwork in the past and present, and may be particularly applicable to literature which upholds a traditional conception of authorship.

\section{Methodology}

Critical Discourse Analysis (CDA) developed from Michel Foucault, Laclau and Mouffe and Norman Fairclough formed the methodology and its philosophical underpinnings. CDA is not prescriptive and practitioners use a range of approaches depending on their purposes and data, but there are certain principles that underpin all forms of the practice.

Michel Foucault is typically considered the founding philosopher of CDA (see e.g., (Fairclough, 2003, 1993; Wetherell et al., 2001) for his arguments that language is less like a vehicle conveying meaning than the instrument by which meaning is constructed. There is no pre-extant truth behind language, only 'regimes of truth' constructed and maintained through social communication. For example, in his book Birth of the Clinic, Foucault (1976b) set out to write a cultural history of medicine. He discovered as he worked that there is no pre-existing object called 'medicine' prior to or outside language, but that 'medicine' is a discursive construction authorized, upheld, enacted and contested by certain institutions and individuals whom we invest with greater or lesser authority to do so. This, Foucault (1976b) contends, is the state of reality - essentially he makes an anti-theological argument concerning truth and meaning. How we communicate structures reality, and statements gain strength and solidity from repetition and distribution. In The Archaeology of Knowledge, Foucault called this property of statements their 'repeatable materiality' (Foucault, 1976a). He utilized the image of a tree to help convey his concept of discourse formations at their roots are 'governing statements', which provide the foundation. These governing statements cannot be contradicted by the rest of the discourse. At the peripheries - the branches of the tree are a whole range of statements, some weaker, some stronger, and these may be in conflict: the discourse formation 'medicine' might include both 'statins are beneficial' and 'statins are dangerous', but neither of these would contradict a governing statement such as 'medicine is the study and treatment of the human body in illness', or something similar. Statements move in and out of discourses over time: previous cultures' medical discourses included all manner of statements we have now disregarded (the theories of bodily humours spring to mind) whilst our construction of medicine now includes certain social and psychological statements which would previously have belonged to other domains. The task of a critical discourse analyst is to chart a discourse - to discover its limits, grounding statements and conditions - at a particular point in time, and demonstrate its processes of change.

Norman Fairclough developed CDA by demonstrating how each indi- vidual text is made out of the echoes of earlier texts, often from disparate genres. Statements carry shadows of meaning from earlier usages, even as their recombination changes and renews their meaning. An article in a tabloid on a promising new drug might combine several lexes, those from the discourse of accepted science imbuing it with authority whilst statements sourced in religion (miracle, hope, revelation) shape the human interest angle. This kind of intertextuality and interdiscursivity naturally create much of the meaning of fanwork, as citations from the source text are self-consciously contrasted with statements from other genres, tropes, and styles.

The study took precedent from Fairclough's work in attention to these stylistic operations. However, many previous discourse analyses have been weakened by a failure to discuss the reception of statements in their context. The research was intended to explore how fanfic received, shaped and altered the concept of authorship. Thus it needed to demonstrate what kind of statements were approved, which rejected, which celebrated and recommended. Luckily, the fannish practice of reviewing and recommendation made this simple - if time-consuming - to document. In each of the major research chapters, it was first considered how the discursive formation (of masculinity, authority or authorship respectively) was constructed in the source text. This was accomplished by close textual analysis suited to televisual drama, taking account of the script, production and official paratextual materials. As patterns began to emerge, the author was able to identify the 'governing' statements at the basis of each construction for example, it was discovered that whilst Game of Thrones' construction of authority was highly fragmented and diverse, authority was always constructed as dependent on belief and acceptance on behalf of those over whom it was exercised. This was therefore, a grounding statement of the discourse formation - a condition upon which the other statements all rested.

The study then moved on to explore the related fanfic at 3 of the web's most popular hosting sites: Fanfiction.net; LiveJournal and the Archive of Our Own. My own history in fandom gave me insight into where to begin my searching and how to navigate these sites - in each case, the researcher began by searching with the site's tags, filters or other mechanisms for fanfic pertinent to the discursive formation in question. The researcher read all the relevant stories closely - a total of 402 for Sherlock, 154 for Game of Thrones and 704 for Supernatural, ranging in length from 100-word drabbles to multiple-hundred thousand-word epics. There were no shortcuts possible here - large-scale discourse analysis does take a large amount of time and attention, but it is really the only reliable way of demonstrating how changes in ideas and ideologies take place. As was explained in the methodology chapter:

I established versions of what network analysts call 'ego networks' (Beaulieu, 2005) for each fic by searching for the title and/or author in quotation marks, always remembering that the context of a connection bears on its importance in a network Park \& Thelwall (2003). This part of the process has an unavoidable margin of error: occasionally, where both the title and username were very common words, I had to enclose '[title] by [author]' in quotation marks, and thus may have missed some references. A titleand-author reference, whether a recommendation or a negative comment, almost always takes the form of a hyperlink. I began these searches with Google, as it is the world's mostused search engine, then repeated them on Yahoo and Bing, the world's second-and-third most used search engines at the time this research commenced. After these the market share in search engines drops dramatically, so it is unlikely that further engines would yield more relevant data (Fathallah, 2017). 


\section{Results and Discussion}

In this way, the study was able to establish and demonstrate the construction and alteration of the of discourse formations masculinity, authority and authorship. An example of the way these processes were illustrated will now be provided. The last example from the book is utilized here, which brought together the themes of the project to examine how fandom changed the construction of authorship in Supernatural. All diagrams are from Fanfiction and the Author, published Amsterdam University Press in 2017, at p. 160 and p. 169. Fig. 1 is based on the statements drawn from the series itself, whose metatextual construction of authorship is based on the characters of Chuck Shurley and Becky Rosen. Shurley is a neurotic alcoholic and stereotypical geek, who makes his living as pulp novelist due to the mystical visions he receives of the show's actual protagonists on their adventures.

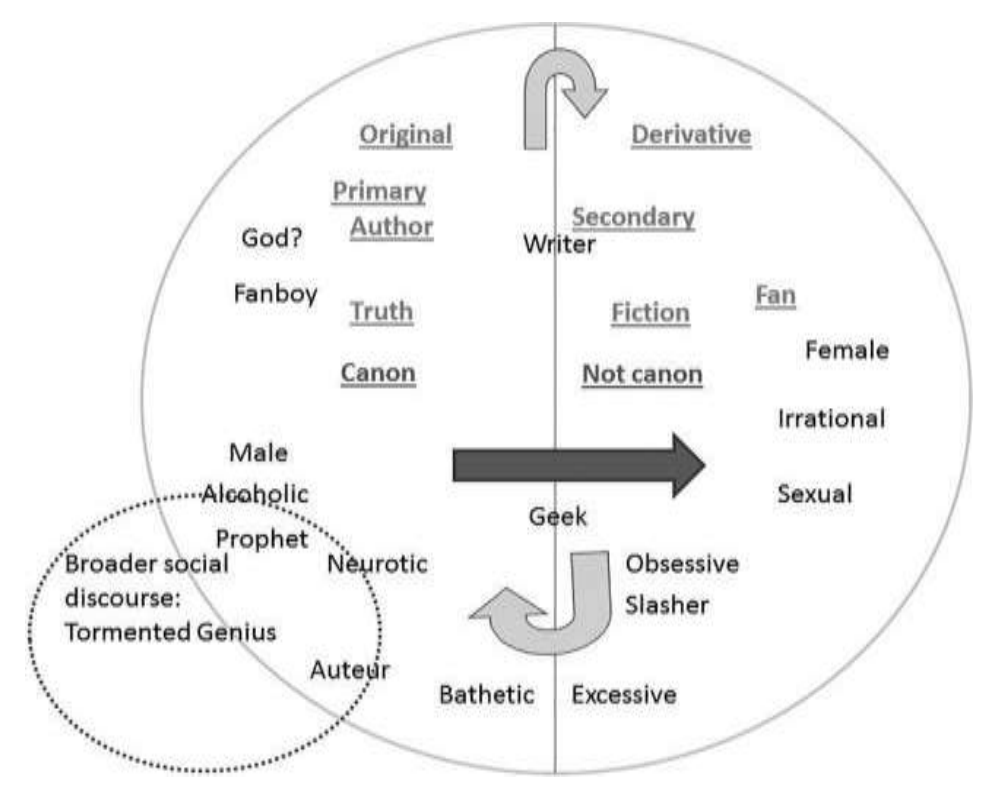

Fig. 1. The construction of authorship (by its negative) in Supernatural.

As the diagram illustrates, the concept of authorship was diegetically constructed by contrast with its posited 'opposite', i.e., fandom. Construction through opposition is a common means of definition in discourse formations (consider: woman/man, West/East, good/bad). Within the show's diegesis, fandom is constructed primarily through the character of Becky Rosen, a huge fan of Chuck's books. As the show's fourth and fifth season progresses, Chuck learns that the 'characters' he thought were figments of his inspired imagination are real people within the diegesis of the show, whilst Becky has a good fortune first to be contacted by her favourite author and then to learn that the series of books she loves most is actually an account of real events. (Her exclamation of "I knew it!" is a nod to Galaxy Quest, an affectionate satire on geek culture and fandom). As the diagram shows, she is constructed as feminine, comic, hysterical and sexualized to Chuck's brand of geek masculinity. Chuck stands in metatextual for the real writers of the show, specifically the original creator in the person of Eric Kripke. Kripke is a key example of what Scott $(2011,2019)$ called the 'fanboy-auteur': A geeky, amicable and fan-friendly persona assumed by certain male writers in the cult TV industry whilst of course retaining economic, industrial and cultural power over the text and largely determining its direction. Chuck enters into a relationship with Becky - writers need their fans - and tolerates her writing fanfiction about his characters.
Nonetheless, it is quite clear within the show's diegesis that his output is the true and real text - he is, after all, quite literally a prophet. There is even a coda to the final episode of the 5-season arc Eric Kripke designed, humorously implying Chuck might be not just a prophet but God himself (the original Author and traditional source of inspiration for gifted writers). The small, outer circle on the diagram illustrates how the construction of Chuck as an alcoholic taps into a broader cultural discourse of tormented artists and geniuses. Carabine (2001) calls this process 'hooking' - a technique by which a single statement can do a large amount of definitional work via pre-constructed cultural associations. The research concluded that, according to the official text, there were two interdependent grounding statements in the discursive construction of authorship: that the Author's text is true, canonical and real, and the fan's writing, though permissible, is secondary, derivative and imaginary.

After working through the methodological process designed above, the researchers concluded that the construction of authorship in Supernatural fanfic separated the concept of authorship from fandom. There were plenty of stories featuring only Becky or only Chuck, and explicitly contributing to only one side of the dyad. When the investigation was finished, the new discursive formations were represented as follows: 


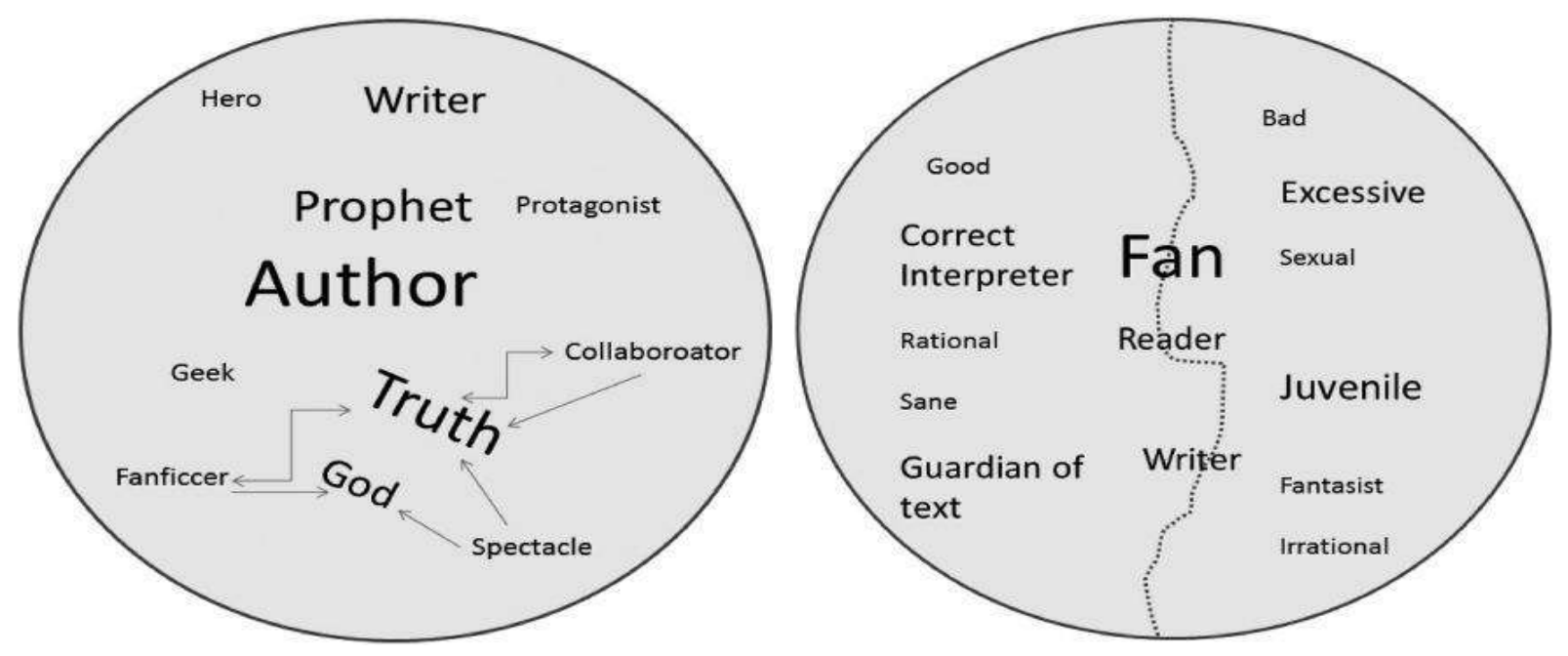

Fig. 2. Fandom's reconstruction of authorship

The larger font represents statements that were more impactful (i.e., received more reviews, reblogs and quotations) and smaller font represents those that were present but did not make much impact on the formations. Obviously there is not space here to rehearse in detail the analysis of the stories and reviews, but a quick summary is provided below.

As illustrated by the diagrams:

- Fanfic constructed the author and the fan as independent characters who sometimes interact

- The author's relationship with truth was destabilized through a variety of stories on the relationship between his writing and diegesis

- There were a range of popular metatextual stories destabilizing the concept of authorship, including dissection of the concepts of sole authorship, collaboration, fallibility, knowledge and divine authorship

- The construction of fans as largely feminine, hysterical and hypersexualized was not contradicted in the fanfiction, but rather separated off into Other 'bad' fans, immature and silly viewers or readers who like texts for the wrong reason, and 'good' fans, mature, witty and properly appreciative critics with whom the reader and writer are identified

- There were a couple of meta-textual stories explicitly discussing fanfiction's ability to 'change' discourse, considering truth claims from a postmodern perspective arguing for relativity and the ability/right of all writers to contribute to social discourse

- However, there was a stronger and more pervasive tendency for fanfic and fan practices to be legitimated via reference to the character of the author, or the concept of authorship. For example, Becky may be depicted as the only person who can properly interpret the 'prophet's texts. She might justify fanwork be attempting to demonstrate that it is valid, or almost as valid as, professionally published authorship, and/or the story might explore these themes meta-textually.

This last point was the culmination of a paradox that was identified across the formations, the paradox of legitimation. In Sherlock, the title character is a construction and demonstration of a particular kind of English masculinity, explicitly used a role model for such since his first appearance in the Conan Doyle stories. Whilst fandom contributes a huge variety of statements on gender, ethnicity, masculinity, femininity, minds and bodies, the patterns of variation were ultimately justified and legitimated with reference to what Sherlock/Sherlock really is: the civilized White man. In Game of Thrones, a book and television series explicitly concerned with the justification of power, authority is ultimately justified by a mixture of charismatic and traditional principles. The contributions of fandom were surprisingly faithful to the text, and legitimated themselves with reference to the series author George R. R. Martin and the showrunners David Benioff and D. B. Weiss (the study offers several context-specific hypotheses as to why this might be the case in (Fathallah, 2017). Supernatural fandom's impact on the discursive formation of authorship is the most explicit example of the legitimation paradox at work. A similar pattern has been identified in postcolonial literature and art: in order to effect change and challenge the authority of canonical predecessors, one must necessarily engage with them, thus appealing to it for the legitimation required to make its criticisms. As one might expect, fanfic has developed to a point wherein it directly addresses, satirizes and discusses the paradox, assuming multiple writing personas and even utilizing multimedia formats to deconstruct it.

Thus, the research has demonstrated a qualitative/quantitative method that allows the discourse analyst to make evidentiary statements on how discourse formations are changed. The process allowed the researcher to empirically establish the development, shape and incipient deconstruction of the legitimation paradox, which will certainly undergo further change and development as showrunners take more and more explicit notice of their fans. Moving beyond strictly fanfiction to the multimedia formats supported by the micro-blogging site Tumblr, the author was able to explore some of the ways that fans have ultilized multisemiotic channels in the deconstruction of the legitimation paradox. Tumblr is notoriously unstable and difficult to search, so it is harder to establish authoritative quantitative data on this site than on the sites devoted to fanfiction in text form. Nonetheless, in research concerned with anti-fandom or the forms of fanlike attention media watchers pay to texts they explicitly dislike, the researcher located a great deal of pertinent material. In searching Tumblr for the keywords "Sherlock AND hate" and following result links, I discovered the anti-fan blogs:

a. sherlocksucks.tumblr.com

b. anti-bbcsherlock.tumblr.com, which describes itself in measured tones as 'an archive for people who dislike BBC Sherlock'

c. why-helo-is-i-stvenen-mofat.tumblr.com.

The title of this final blog includes a deliberate misspelling of the name Steven Moffat, who is a cult television writer, producer and former showrunner for Sherlock. As I established,

Their very titles deny their own claims to authoritative voice, via the obvious misspelling and grammatical inversion of 'is-i-stvenen-mofatt.' 'Is-I' is a grammatical question: each reader must judge the authority of the claim for themselves. Via citation and incorporation into each other's tex- 
Journal of Management Practices, Humanities and Social Sciences 3(1) 6-11

tual format, all the anti-Sherlock blogs become part of each other, in addition to their constant citation of and interaction with Sherlock fandom and the show itself (2018).

The particular affordances of Tumblr, dependent on intertextuality, embedding, citation and fragmentation, create a postmodern pastiche effect. They recirculate serious criticisms of the show, such as lack of character development:

'Remember when Sherlock was literally getting tortured and his brother was treating it all like a joke and then Sherlock was magically fine and it was never mentioned again... Because Moffat's characters do not have emotions, and PTSD just means you're bored'

(post at Tumblr (n.d.), Reblogged from rjalker (2015))

These comments are interspersed with absurdist satire as the 'whyhelo' blog poses as the incoherent voice of a showrunner at odds with his fanbase, and is reblogged by the other accounts alongside the serious criticisms. Tumblr allows questions to be submitted to accounts, which are then publically reblogged and answered as below:

'Anonymous' asks:

'y is Irene not lesbian after seeing Sherlocke' why-helo-is-i-Stvenen-Mofatt:

'HOW BOUT FLUID SXEUALTIY? Um $r$ u hmomphobia? All women fall for Shrelock he MYSTERYIOUS and SXYE. They want DESFROTS GLCACIER and make him HUBSAND. IRENE is STRONG WOMEN with GUN AND SASS and U $R B U L L Y B Y E^{\prime}$

(post at Tumblr (n.d.), Reblogged from why-helo-is-i-stvenen-mofatt (2014))

The question refers to a controversial decision in the script for the episode 2.1, A Scandal in Belgravia wherein the lesbian character Irene Adler apparently fell in love with Sherlock upon meeting him. The answer plays on two common criticisms of Moffat as a showrunner - that his female characters are shallow and unbelievable; and that he cannot take criticism, exaggerating these tendencies to comedic excess. Moffat notoriously claimed that female fans of Sherlock were attracted to the unemotional title character because each believed they would be the woman to 'defrost that glacier', but were all wrong, as 'nothing will melt that glacier' $\mathrm{Ng}$ (2014). This 'stvenen mofatt' responds to any suggestion of criticism with comedic accusations of bullying (or 'BLUYLULING' as the case may be). Yet even as the traditional authorial voice is undercut and ridiculed, the Tumblr blogs equally turn that critique on themselves, their own postures of authority and their claims to authority of fandoms. Because the format integrates reblogs into each microblog's template, there is no visual or semantic border between these sorts of reblogs and the poses of authoritative criticism. Moreover, the parodic tone is used self-reflexively, as when a user named Carinaroundvevo posts 'I used to like Sherlock and now I have repented from those bad days thanks to this blog, god bless you' and receives the response 'God bless YOU, Carinaroundvevo. Welcome to the light', which is then reblogged in several places. The hyperbolic pose of critical awareness in the language of religious salvation parodies its own stance. Some analysis of these processes is begun in Fathallah (2018), but this line of research is just developing, and could be applied and adapted to a wide range of multimedia fanwork and indeed, other kinds of transformative work but researchers from different specialities.

\section{Limitations and Future Research Directions}

As fans experiment with multimedia and multisemiotic texts whose very formats question the traditions of authorship, in addition to conventions of content, there is a great deal more work to be done on how these ideologies will operate in the future, in this context of rapidly changing re- lations between the media industry and its audience. Schäfer's otherwise thoughtful book could be criticized for lack of attention to what kinds of UGC tend to receive what kind of corporate response, and how these trends relate to the corporation's values and practices. This is an important avenue for future study, Scott (2011) identified a gender divide between the approved fannish production (primarily masculine, e.g., vid creation from licensed material) and non-approved (primarily feminine, e.g., fanfiction focusing on feminine and queer relationships). Clearly, there is not going to be any set list of instructions for the successful, profitable and ethical integration of fanwork, but this is a second important direction for future research. As some initial suggestions, each franchise must consider a range of issues, including

- Labour and exploitation

- What kinds of fanwork are valued, and why? By what system of value?

- Protection of brand image

- How far ownership over ideas can extend

- Fan goodwill and loyalty

- Any issues particular to the property in question.

\section{Conclusion}

This research has established that the operations of the legitimation paradox have underpinned a great deal of fanwork in the past and present, and may be particularly applicable to literature which upholds a traditional conception of authorship (see also Fathallah (2016a,b)). However, a number of avenues are there to be explored.

How are media industries responding to these changes thus far? Schäfer (2011) has suggested that industry responses have largely fallen into three categories, which he calls:

a. Confrontation: This strategy aims to prevent users from challenging established business models; e.g., by sending cease and desist letters to fansites and claiming copyright infringement

b. Implementation: which attempts to utilize User-Generated Content (UGC) in new revenue models e.g., by utilizing fanwork as free advertising. c. Integration: which seeks to involve new media practices in sociopolitically responsible ways.

The problems with confrontation are multiple. Firstly, it obviously does not work - George R. R. Martin once notoriously attempted to ban fanfiction via a blogpost, demonstrating a poor grasp of copyright law in the process; secondly, that it might not be legal (fanwork is the very definition of a grey area when it comes to copyright and may well fall under a fair use/fair dealing exception depending on content, especially when it is freely distributed); but thirdly and most significantly, confrontation is an excellent way of generating ill will towards a franchise, compromising the loyalties of one's most important audience members. The second option, implementation, is increasingly popular with media companies: HBO, for example, ran a fan competition for Game of Thrones artwork to be posted to a Tumblr account, of which it chose the best examples for publication to its own profit, not the fan artists'. The problem here again is the risk of generating ill will - though on one hand fans may simply be happy with the opportunity for promotion and visibility, the exploitation of fans' labour is rather obvious. It also runs a risk Kristina Busse recognized earlier in the development of fan studies, of

'legitimizing fannish activities and artifacts through various modes of convergence may create a two-tiered fan system of acceptable and non-acceptable fan productions by dividing the fan activities into those approved/encouraged by the producers and those that are not, legitimating the former and further ostracizing the latter...' Busse (2006).

Media property owners face unavoidable changes in how franchises will be negotiated with fan cultures, and whilst there is no way to create 
a set formula or list of instructions for this rapidly developing landscape, issues of labour, brand image and fan goodwill are central to the coming challenges.

\section{References}

Beaulieu, A. (2005). Sociable hyperlinks: An ethnographic approach to connectivity. In C. Hine (Ed.), Virtual methods: Issues in social research on the internet (p. 183-198). New York. NY: Berg.

Busse, K. (2006). Podcasts and the fan experience of disseminated media commentary. Retrieved from https://bit.1y/2PTyaqS

Carabine, J. (2001). Unmarried motherhood 1830-1990: A genealogical analysis. In . S. J. Y. M. Wetherell S. Taylor (Ed.), Discourse as data: A guide for analysis (p. 267-307). London, UK: Sage. Retrieved from https://bit.ly/2BluKVq

De Kosnik, A. (2016). Rogue archives: Digital cultural memory and media fandom. Cambridge, MA: MIT Press.

Dyer, R. (1997). White: Essays on race and culture. London, UK: Routledge.

Fairclough, N. (1993). Discourse and social change. London, UK: Polity.

Fairclough, N. (2003). Analysing discourse: Textual analysis for social research. London, UK: Psychology Press.

Fathallah, J. (2016a). 'Except that Joss Whedon is god': Fannish attitudes to statements of authority. International Journal of Cultural Studies, 19(4), 459-476. doi:https://doi.org/10.1177/1367877914537589

Fathallah, J. (2016b). Statements and silence: Fanfic paratexts for ASOIAF/Game of Thrones. Continuum, 30(1), 75-88. doi:https://doi.org/10.1080/10304312.2015.1099150

Fathallah, J. (2017). Fanfiction and the author: How fanfic changes popular cultural texts. Amsterdam, Netherlands: Amsterdam University Press.

Fathallah, J. (2018). Polyphony on Tumblr: Reading the hateblog as pastiche. Transformative Works and Cultures. Retrieved from https:// bit.ly/2MRwrPt

Foucault, M. (1976a). The archaeology of knowledge. New York, NY: Routledge.
Foucault, M. (1976b). The birth of the clinic. London, UK: Tavistock Publications Ltd.

Gray, J. (2010). Show sold separately: Promos, spoilers, and other media paratexts. New York, NY: New York University Press.

Hills, M. (2003). Fan cultures. New York, NY: Routledge.

Hills, M. (2010). Triumph of a time lord: Regenerating doctor who in the twenty-first century. London, UK: Bloomsbury Publishing.

Mirmohamadi, K. (2014). The digital afterlives of Jane Austen: Janeites at the keyboard. London, UK: Palgrave Macmillan.

Ng, P. (2014). 'Sherlock' boss on 'moving' Holmes/Watson reunion and 'funnier' season 3 (Q\&A). Retrieved from https://bzfd.it/20Y J3XO

Park, H. W., \& Thelwall, M. (2003). Hyperlink analyses of the world wide web: A review. Journal of Computer-Mediated Communication. Retrieved from https://bit.1y/2pALcyL

rjalker. (2015). Too insane for words. Retrieved from https://bit.ly/ 2CqtzEu

Schäfer, M. T. (2011). Bastard culture! how user participation transforms cultural production. Amsterdam, Netherlands: Amsterdam University Press.

Scott, S. (2011). Revenge of the fanboy: Convergence culture and the politics of incorporation (Unpublished doctoral dissertation). University of Southern California, Los Angeles, CA.

Scott, S. (2019). Fake geek girls: Fandom, gender, and the convergence culture industry. New York, NY: NYU Press.

Tumblr. (n.d.). Antibbcsherlock. Retrieved from https://bit.ly/ 2BRS90Q

Wetherell, M., Taylor, S., \& Yates, S. J. (2001). Discourse as data: A guide for analysis. Thousand Oaks, CA: Sage.

why-helo-is-i-stvenen-mofatt. (2014). Tumblr. Retrieved from https:// bit.ly/332KiJo 